\title{
Religião, periferia e leitura popular da Bíblia: uma análise do documentário Santa Cruz à luz da pneumatologia pentecostal
}

\author{
Religion, periphery and popular reading of the Bible: an analysis of the Santa Cruz \\ documentary in the light of Pentecostal pneumatology
}

\author{
Samuel Silva da Costa* \\ Roney Ricardo Cozzer**
}

\begin{abstract}
Resumo
O presente artigo faz uma análise do Documentário Santa Cruz, gravado em 1999, que retrata o desenvolvimento de uma pequena igreja de matriz pentecostal que opera em Santa Cruz, uma comunidade carente do Rio de Janeiro. O Documentário, dirigido por João Moreira Salles, acompanhou durante o período de um ano o desenvolvimento da igreja "Casa de Oração Jesus é o General", e registrou diversos momentos dessa pequena comunidade eclesial. O objetivo do presente texto é observar como a interação religiosa dessas pessoas e sua relação com a Leitura Popular da Bíblia irá gerar benefícios sociais concretos em suas próprias vidas e na comunidade inteira, respondendo assim à pergunta: Qual o impacto causado por uma igreja evangélica atuante? Para tanto, estabeleceu-se um diálogo com autores como Antonio Gilberto, teólogo pentecostal, e Frei Carlos Mesters, que pesquisou extensivamente o tema da Leitura Popular da Bíblia.
\end{abstract}

\section{Palavras-chave}

Documentário. Religião. Pentecostal. Leitura.

\begin{abstract}
This article does an analysis of the Santa Cruz Documentary, filmed in 1999, which portrays the development of a small Pentecostal church which operates in Santa Cruz, a poor community in Rio de Janeiro. The Documentary, directed by João Moreira, accompanied the development of the church "House of Prayer Jesus is the General", during one year and
\end{abstract}

[Texto recebido em janeiro de 2018 e aceito em janeiro de 2018, com base na avaliação cega por pares realizada por pareceristas ad hoc]

* Bacharel em Teologia. Pós-Graduado em Ciências da Religião pela Faculdade Unida de Vitória. E-mail: samuelsilvacosta@hotmail.com

** Bacharel em Teologia. Licenciado em História e Pedagogia. Pós-Graduado em Metodologia do Ensino de História e Geografia e Psicopedagogia Clínica. Possui formação em Psicanálise Clínica. Mestrando em Teologia pela Faculdades Batista do Paraná. Membro do Grupo de Pesquisa "Perquirere: Práxis Educativa na Formação e no Ensino Bíblico". Articulista do Portal Seara News. Atualmente participa como autor e pesquisador do Projeto Historiográfico do Departamento de Missões das Assembleias de Deus do Vale do Rio Doce e Outros (DEMADVARDO). E-mail: roneyricardoteologia@gmail.com 
registered various moments of this small ecclesial community. The goal of this text is to observe how the religious interaction of these people and their relation to the Popular Reading of the Bible generate concrete social benefits in their own lives and in the whole community, thus answering the question: What is the impact caused by an active Evangelical church? To do this, a dialog was established with authors such as Antonio Gilberto, a Pentecostal theologian, and Friar Carlos Mesters, who did extensive research on the Popular Reading of the Bible.

\section{Keywords}

Documentary. Religion. Pentecostal. Reading.

\section{Introdução}

O Documentário Santa Cruz ${ }^{1}$ retrata a história de uma pequena comunidade eclesial no Rio de Janeiro, no ano de 1999, na cidade de Santa Cruz, donde deriva o nome do documentário. Essa comunidade denominada "Casa de Oração Jesus é o General", de matriz Pentecostal, foi acompanhada pela equipe do documentário no período de um ano, sendo os "atores" os próprios membros dessa pequena igreja, ${ }^{2}$ pessoas anônimas e muito simples, vivendo numa área de grande fragilidade social. O Documentário é dirigido por João Moreira Salles, carioca, cineasta, escritor e jornalista. Têm em seu currículo outros documentários, como Noticias de uma Guerra Particular, O Vale, Lavoura Arcaica, Nelson Freire, Enteados e Santiago. ${ }^{3}$ É perceptível em seus trabalhos cinematográficos a forte ênfase dada a questões de cunho social como política, religião, violência urbana, dentre outras, trazendo à tela a realidade brasileira, como que propondo um diálogo com a sociedade brasileira. Nesse documentário em particular, aqui abordado, o cineasta mostra uma realidade por muitos desconhecida e, intencionalmente ou não, acaba por mostrar como uma igreja evangélica influencia positivamente toda uma comunidade ao seu redor, na qual ela mesma está inserida.

Não há um apresentador, apenas uma locução que vai narrando os detalhes do documentário na medida em que ele avança. Fica evidente no decurso do documentário como os membros dessa igreja tiveram suas vidas mudadas de forma positiva dada a influência da vivência com esse grupo de "irmãos". A igreja é liderada pelo Pastor Jamil Alves da Silva, um metalúrgico aposentado que faz suas locomoções de bicicleta atravessando assim a carente comunidade de Santa Cruz. Seu destino é o Parque Florestal, lugar distante dos direitos constituintes, como saúde, educação e segurança pública. O local é habitado por uma maioria de imigrantes nordestinos. É nesse contexto que está localizada a sua igreja, com bancos de madeira e um pequeno púlpito de onde ele profere suas prédicas.

1 Documentário Santa Cruz. Disponível em: <www.youtube.com/watch?v=JTfWttDRPW8\&t=1776s>. Acesso em: 28 nov. 2017.

2 O termo "igreja" aqui se refere justamente a essa comunidade eclesial local. O termo não é usado aqui em seu sentido lato, que inclui as diversas denominações protestantes.

3 Disponível em: <educacao.uol.com.br/biografias/joao-moreira-salles.jhtm>. Acesso em: 28 nov. 2017. 
A análise do documentário pode ser feita por diferentes dimensões, mas busca-se aqui fazê-lo sobre as seguintes temáticas: religião e periferia, a Pneumagiologia ${ }^{4}$ pentecostal muito presente no pensamento dos membros da igreja e como a Leitura Popular da Bíblia se faz sentir entre eles. Importante destacar ainda que serão considerados neste texto elementos sociológicos, teológicos e de espiritualidade observados na própria realidade vivencial dessa comunidade eclesial e que são captados, naturalmente, pelo documentário.

\section{Pneumagiologia pentecostal}

Apesar de estar muito atrelada à Pneumagiologia clássica do Pentecostalismo, a espiritualidade observada na comunidade eclesial de Santa Cruz acaba não escapando da realidade do sincretismo, observado no Protestantismo Brasileiro em suas diversas matrizes denominacionais. Como bem observa Mendonça:

Se o protestantismo tradicional resistiu à ameaça do sincretismo e manteve até certo ponto a pureza da mensagem missionária original, é no pentecostalismo que vamos encontrar formas bastante claras de sincretismo. A matriz teológica do pentecostalismo é o protestantismo tradicional na sua expressão não clerical. Assim, a mensagem missionária, portadora de uma teologia simples e facilmente assimilável como a da Era Metodista, constitui a base sobre a qual o movimento pentecostal ergueu seu próprio arcabouço sincrético, em que estão presentes antigos traços históricos da Igreja cristã, elementos do catolicismo popular e dos cultos

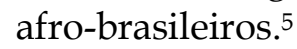

Os membros dessa comunidade acreditam na Bíblia como Palavra de Deus, e noutros slogans típicos do Protestantismo. Ainda assim, consideram um salmo mais "forte" que outro. Acreditam na pessoa e na operação do Espírito Santo nos típicos moldes da Pneumagiologia pentecostal, Pneumagiologia que é, naturalmente, refletida nos ditos e expressões dessa comunidade eclesial.

Duas disciplinas da Teologia Sistemática que sempre tiveram papel de destaque no Movimento Pentecostal são a Pneumagiologia e Escatologia. 6 Elas podem ser

4 O termo é formado à partir de uma junção de três palavras gregas e significa "Estudo do Espírito Santo" (hagios no grego significa "santo") e é o nome dado à uma das disciplinas da Teologia Sistemática (ou Dogmática, como também é chamada esta área da Teologia). Optou-se por este termo, no presente artigo, por ser mais específico em sua definição, em lugar de Paracletologia, que significa simplesmente "estudo do consolador", e de Pneumatologia, que significa "estudo do espírito". Pneumagiologia é assim mais preciso que os outros dois termos. Embora "Pneumagiologia" não seja muito usado nas Teologias Sistemáticas, ele é o que mais e melhor especifica o objeto de estudo da disciplina.

5 MENDONÇA, Antonio G. Protestantes, Pentecostais e Ecumênicos: o campo religioso e seus personagens. UMESP: São Paulo, 1997. p. 150.

6 A Escatologia é a disciplina da Teologia Sistemática que estuda os eventos finais na perspectiva bíblica. Ela possui três grandes ramos ou correntes, a saber: o Amilenismo, o Pós-Milenismo e o Pré-Milenismo, tendo este último ramo algumas vertentes. O Movimento Pentecostal majoritariamente aderiu ao Pré- 
consideradas molas propulsoras por nortearam convicções, liturgia, as homilias e até a "Teologia Pentecostal" como um todo. É claro que no contexto e na produção teológica do Movimento Pentecostal, elas ganharam contornos bem específicos e sui generis, em relação a como foram processadas e dissecadas nas outras confissões históricas do Cristianismo. Como exemplo dessa peculiaridade aqui mencionada, considere-se a questão de como se interpreta o uso e o continuum do batismo com o Espírito Santo e os dons espirituais, entre outras questões atreladas a isso, no pensamento pentecostal.

A despeito da grande disputa e discórdia que tem havido quanto a alguns elementos da Pneumagiologia entre pentecostais, liberais e reformados, é inegável a contribuição do Movimento Pentecostal para a Pneumagiologia na Teologia Cristã. É dito que Teologias Sistemáticas antigas, anteriores ou até mesmo bem subsequentes ao boom de crescimento do Movimento Pentecostal, mormente a partir de 1906, com destaque em Azuza Street, sequer traziam um capítulo sobre a questão do batismo com o Espírito Santo. Entende-se que houve assim certa negligência quanto a esta parte importante e fundamental da Teologia Cristã no que concerne à produção literária. Podemos afirmar que a forte ênfase dada pelo pentecostalismo à pessoa e à obra do Espírito Santo praticamente exigiu que se discutisse e se escrevesse sobre questões como essa em Pneumagiologia. Wayne Grudem comenta:

Tradicionalmente, os livros de teologia sistemática não têm incluído um capítulo sobre o batismo no Espírito Santo nem sobre a plenitude do Espírito Santo como parte do estudo da "ordem de salvação", os passos através dos quais os benefícios da salvação se aplicam à nossa vida. Mas com a disseminação do pentecostalismo que se iniciou em 1901, com a influência bem ampla do movimento carismático nas décadas de 1960 e 1970 e com o notável crescimento das igrejas pentecostais e carismáticas pelo mundo inteiro desde 1970 até o presente, a questão de um "batismo no Espírito Santo" distinto da regeneração adquiriu maior proeminência. ${ }^{7}$

De fato, de 1906 para cá, diversas obras do campo da Dogmática vêm discutindo o tema Espírito Santo. Diversos teólogos vêm se debruçando sobre o tema, legando extensos comentários sobre o assunto. As teologias sistemáticas produzidas atualmente dificilmente deixam de incluir um capítulo ou parte sobre o tema.

Uma tônica sempre constante na Pneumagiologia Pentecostal é a ideia de que o continuísmo do batismo com o Espírito Santo e dos dons espirituais integram o evangelho na sua totalidade, negar isso, portanto, é negar parte essencial do evangelho. Mark D. McLean, teólogo pentecostal, reflete esta compreensão, quando afirma:

Milenismo, especificamente o Pré-Milenismo Dispensacionalista, sendo o Dispensacionalismo uma dessas vertentes.

7 GRUDEM, Wayne A. Teologia Sistemática. São Paulo: Vida Nova, 1999. p. 635. 
A tarefa dada à Igreja do século XX é pregar a totalidade do Evangelho. O que necessitamos não é um evangelho diferente, mas a plenitude do Evangelho conforme registrado no Novo Testamento. Destacamos este fato, porque o Espírito Santo tem sido negligenciado no decurso dos séculos. Temos a tarefa de entender de novo a Pessoa e a obra do Espírito Santo, conforme reveladas na Bíblia e experimentadas na vida da Igreja hoje [...] A mensagem do Evangelho pleno diz que Deus continua a falar e a agir, como nos tempos do Antigo e do Novo Testamento. ${ }^{8}$

Para os pentecostais, o batismo com o Espírito Santo é tanto uma bênção concreta, com evidência física, quanto uma promessa espiritual. Teólogos pentecostais procuram indicar textos no Antigo e Novo Testamentos que confirmem a atualidade desse batismo. No início do Movimento Pentecostal, houve até uma forte ênfase na xenolalia, ${ }^{9}$ o que gerou um

interesse generalizado pelo batismo e dons do Espírito Santo [que] convenceu alguns de que Deus concederia o dom de línguas a fim de equipá-los com idiomas humanos identificáveis (xenolalia) para que pudessem anunciar o Evangelho noutros países, agilizando assim a obra missionária. ${ }^{10}$

Mas afinal, o que é esse batismo com o Espírito Santo? Discute-se muito nos círculos teológicos e eclesiásticos se ele continua sendo de fato para os dias de hoje, mas o assunto continua ainda muito confuso na cabeça de muitas pessoas. Grudem traz em sua Teologia Sistemática (1999) uma discussão não apenas no sentido de conceituar o tema em questão, mas até de situar quando se dá esse batismo, o que por sua vez, tem relação estreita com a compreensão do que é esse batismo. ${ }^{11}$ Para Antonio Gilberto, teólogo pentecostal brasileiro reconhecido internacionalmente, ${ }^{12}$ o batismo com o Espírito Santo

É um revestimento e derramamento de poder do alto, com a evidência física inicial de línguas estranhas, conforme o Espírito Santo concede, pela instrumentalidade

8 McLEAN, Mark D. O Espírito Santo. In: HORTON, Stanley M. (Ed.). Teologia Sistemática: uma perspectiva pentecostal. Rio de Janeiro: CPAD, 1996. p. 383.

9 Termo oriundo de duas palavras gregas: xenos que significa "estrangeiro", e lalein que significa "falar, palrar". SCHÜLER, Arnaldo. Dicionário enciclopédico de teologia. Canoas: ULBRA, 2002. p. 488. Conclui-se, no contexto pentecostal, que o Novo Testamento indica claramente a ocorrência da glossolalia e da xenolalia. Lawrence O. Richards comenta: "[...] quando o livro de Atos indica que os discípulos cheios do Espírito falavam em outras línguas, o contexto deixa claro que todos os espectadores (partos, medos, elamitas, egípcios, líbios etc.) ouviam a mensagem em sua própria língua nativa (At 2.4-12). Em 1 Coríntios 12 e 14 uma língua não é um idioma inteligível, e requer uma pessoa dotada de 'interpretação de línguas' para tornar a mensagem inteligível (1 Co 12.10)". RICHARDS, Lawrence O. Comentário histórico-cultural do Novo Testamento. 3.ed. Rio de Janeiro: CPAD, 2008. p. 255.

10 McGEE, Gary B. Panorama histórico. In: HORTON, Stanley M. (Ed.). Teologia Sistemática: uma perspectiva pentecostal. 10.ed. Rio de Janeiro: CPAD, 2006. p. 15-16.

11 cf. GRUDEM, 1999, p. 637-642.

12 cf. HORTON, 2006, p. 39. 
do Senhor Jesus, para o ingresso do crente numa vida de mais profunda adoração e eficiente serviço para Deus. ${ }^{13}$

Outro conceito fundante da práxis pentecostal, em vários aspectos, é o que afirma que o continuísmo é para o nosso tempo, de modo que, na compreensão dos pentecostais, todos os crentes têm direito a essa promessa, que é do próprio Pai. Ela deve ser buscada e desejada com intensidade. Isso é visto nas próprias palavras do Pastor Jamil, do documentário, que procura justificar o não recebimento do batismo com o Espírito Santo por ele mesmo. Embora ele não o seja, por ocasião do documentário, afirma desejar receber e aplicar-se para isso. Os cristãos de linha pentecostal entendem que essa experiência era comum e normal na realidade da igreja primitiva, que capacitava os crentes para uma vida de poder: poder no serviço, na adoração, na evangelização, na oração, enfim, os capacitava a uma vida cristã de mais profundidade. A igreja cristã do primeiro século é sempre lembrada no ambiente pentecostal como uma espécie de "modelo" para a Igreja evangélica hoje, no século 21. Se para eles essa era uma experiência comum e normal, porque deveria ser estranha para a Igreja, hoje? Este é um postulado sempre recorrente nas pregações, estudos bíblicos e textos produzidos pelo Movimento Pentecostal.

Enquanto alguns teólogos de linha reformada e tradicional parecem pôr em xeque a questão do momento em que esse batismo ocorre, ou qual é o momento mais adequado para ele ocorrer segundo as Escrituras, para os pentecostais é consenso quase que universal que o batismo com o Espírito Santo é subsequente à salvação, ${ }^{14}$ uma experiência distinta e atrelada a um engajamento pessoal do candidato em uma vida de oração e "busca contínua". ${ }^{15} \mathrm{O}$ batismo com o Espírito Santo também é visto como uma espécie de "porta de entrada" para o recebimento dos dons espirituais. Ser "nascido de novo" (convertido) é condição sine qua nom para o recebimento da "promessa", na compreensão pentecostal do assunto.

\section{Pneumagiologia pentecostal e reflexos práticos}

Para Regina Fernandes Sanches, a Pneumagiologia pentecostal, para ser entendida, precisa ser considerada sob a perspectiva da Teologia Bíblica e a autora chega a propor uma associação com a Teologia da Missão Integral:

Nos tempos da modernidade, seja ela pós ou tardia, o indivíduo tem se deixado inquietar pelo próprio espírito e se predisposto a compreender o

13 GILBERTO, Antonio (Ed.). Teologia sistemática pentecostal. Rio de Janeiro: CPAD, 2008. p. 191.

14 Antonio Gilberto comenta que o batismo com o Espírito Santo "precede os dons espirituais mencionados nas epístolas" e prossegue afirmando que "o batismo com o Espírito Santo é para quem já é salvo". GILBERTO, 2008, p. 191,193).

15 Tal concepção pode também ser atrelada ao sistema soteriológico predominante no Pentecostalismo que, por sua vez, valoriza muito a participação ativa do homem no plano salvífico de Deus: o arminianismo. 
que vai mais além do seu próprio limite humano e de sua materialidade. Cabe, nesse momento de novidade, traduzir a linguagem bíblica sobre o Espírito Santo, considerando certamente o empreendimento de nossa Pneumagiologia histórica, lembrando sempre que, como espírito, ele escapa a qualquer postulado, construção teórica e teológica, por mais bem ordenadas que sejam. ${ }^{16}$

Nota-se que há uma Leitura Popular da Bíblia atrelada ao pensamento teológico no que tange à Pneumagiologia Pentecostal. Em outras palavras, procura-se uma associação estreita e harmônica entre a espiritualidade pentecostal, com suas manifestações carismáticas na realidade da vivência pentecostal, com o que a Bíblia afirma sobre o tema. Ouve-se e lê-se com frequência aquele chavão já conhecido no contexto pentecostal: "A Bíblia diz". Este chavão tornou-se uma espécie de "fórmula" que legitima doutrinas e convicções à luz do contato com as Escrituras. Nesse sentido, a leitura da Bíblia, bem como sua (re)interpretação, tem seu lugar estabelecido. Antonio Paulo Benatte reconhece esse fato:

Os pentecostais constituem comunidades interpretativas da Palavra: a interpretação da comunidade, que, por sua vez, a (re) atualiza; tem-se, assim, um processo dialético de circularidade hermenêutica entre a comunidade e o Livro. Trata-se de um processo complexo de apropriação cultural. No caso da leitura bíblica, havia, juntamente com o analfabetismo, uma barreira cultural à apropriação do Livro. ${ }^{17}$

A questão do continuum do batismo com o Espírito Santo bem como dos dons espirituais, sempre recorrente no pensamento pentecostal, vê-se muito bem refletida na fala do Pastor Jamil que afirma não ter recebido o batismo e por isso não tem os dons espirituais. Na Pneumagiologia Pentecostal essa decorrência, embora discutida, é sempre reafirmada. Os pentecostais sempre tiveram como característica a leitura de textos bíblicos e sua interpretação; o próprio Movimento Pentecostal é entendido como uma forma de continuação do que aconteceu no dia de Pentecostes, como descrito em Atos 2. Assim, há uma forte dependência da Bíblia Sagrada para legitimar suas práticas e convicções. Comentando justamente a Hermenêutica Pentecostal, Robert P. Menzies afirma:

Não, a hermenêutica da maioria dos crentes pentecostais não é excessivamente complexa. Não está cheia de questões sobre a confiabilidade histórica ou repleta de cosmovisões ultrapassadas. Não é excessivamente reflexiva sobre os sistemas teológicos, a distância cultural ou as estratégias literárias. A hermenêutica do crente pentecostal típico é

16 SANCHES, Regina F. Contribuições de uma Teologia Bíblica Integral do Espírito Santo para a Pneumatologia Pentecostal. In: OLIVEIRA, David M. (Org.). Pentecostalismos e transformação social. São Paulo: Fonte Editorial, 2013. p. 22.

17 BENATTE, Antonio P. A formação de leitores da Bíblia no pentecostalismo assembleiano brasileiro. In: OLIVEIRA, David M. (Org.). Pentecostalismos e transformação social. São Paulo: Fonte Editorial, 2013. p. 22. 
direta e simples: as histórias em Atos são minhas histórias - histórias que foram escritas para servir de modelo para moldar a minha vida e experiência. Isso não quer dizer que os pentecostais não exercem discernimento ou julgamento. Afinal, nem todas as histórias estão cheias de façanhas de heróis. Há vilões, e nem todos os aspectos da história devem ser imitados. Entretanto, permanece o fato de que os pentecostais prontamente aceitaram (os detratores diriam acriticamente) as histórias de Atos como nossas histórias, histórias que moldam a nossa identidade, ideais e ações. 18

O texto bíblico se torna assim, uma necessidade premente. No cotidiano da igreja "Casa de Oração Jesus é o General", retratada no documentário, onde por diversas vezes os membros são vistos no documentário com a Bíblia em mãos e lendo textos bíblicos, pode se notar essa clara dependência das Escrituras.

\section{Paradoxo?}

Logo no início do vídeo é lançada uma reflexão pelo diretor do documentário João Moreira Salles: "Por que doutrinas tão restritivas atraem tantas pessoas que já não têm muitas coisas?" De fato, igrejas com o perfil da "Casa de Oração Jesus é o General" parecem produzir uma espécie de dualismo corpo-espiritualidade, ${ }^{19}$ onde práticas que digam respeito a algum tipo de satisfação corpórea e, por que não dizer, o próprio corpo, são sempre vistos com insegurança, desconfiança e em geral, sofrem algum tipo de contenção. A ideia de uma espiritualidade sadia em conexão com um cotidiano que inclui algumas práticas de lazer (por exemplo) parecem estranhas a muitos pentecostais. A despeito desse "dualismo", a pergunta no início do documentário é realmente muito pertinente, pois reflete tanto a realidade religiosa (rigorosa) como a social (com muitas limitações), que se mesclam num aparente paradoxo: pessoas que já sofrem com os limítrofes impostos pelas carências sociais serem atraídas por uma igreja que acaba por impor outras limitações, de cunho religioso com implicações na vida cotidiana, parece realmente estranha e espera-se justamente o efeito contrário: que essas pessoas não buscassem a referida igreja. Todavia, não é o que se verifica na realidade da comunidade eclesial retratada no documentário, que acabou por agregar, em tempo relativamente curto, um número considerável de pessoas da comunidade de Santa Cruz. Tal relação entre convicções religiosas e seus arquétipos e a vida cotidiana não é, de forma alguma, estranha à sociologia. Pode ser percebida nas palavras do sociólogo Émile Durkheim:

18 MENZIES apud CARVALHO, César M. Pentecostalismo e Pós-modernidade: quando a experiência sobrepõese à Teologia. Rio de Janeiro: CPAD, 2017. p. 51-52.

19 Isso é muito recorrente nas igrejas pentecostais. Como exemplo, pode ser citado o Estatuto e RI (Regulamento Interno) da Igreja Pentecostal Deus é Amor, que estabelece regras e normas restritivas de conduta para os membros da denominação que variam desde questões que abordam as vestimentas até a própria higiene pessoal. 
As crenças religiosas são representações que exprimem a natureza das coisas sagradas e as relações que essas mantêm entre si e com as coisas profanas. Enfim, os ritos são regras de comportamento que prescrevem como o homem deve se comportar com as coisas sagradas. ${ }^{20}$

Na espiritualidade pentecostal, a ideia do sagrado e profano é muito forte e é traduzida em usos e costumes rígidos relacionados a que tipo de roupas usar, limitação de algumas modalidades de lazer, dentre outras. A despeito dessa rigidez, o documentário também retrata pessoas que se declaram numa condição atual muito melhor em relação à sua situação anterior, o que pode soar até estranho quando se pensa na realidade social que cerca essas pessoas. Todavia, elas dão relatos em entrevista ao documentário de que sua vida pessoal, familiar e profissional experimentou significativa melhora após "aceitarem a Jesus".

A realidade religiosa vivida pelos membros da igreja retratada no documentário preserva semelhanças com aspectos do avivamento que aconteceu na Rua Azuza, considerado o grande norte do Movimento Pentecostal, nos quesitos cânticos, testemunhos, pregação e mover do Espírito Santo. O historiador do Movimento Pentecostal Isael de Araújo comenta o seguinte:

Em Azuza os cultos eram longos e de forma geral, espontâneos. Nos seus primeiros dias, a música era à capela, embora um ou dois instrumentos fossem tocados. Os cultos incluíam cânticos, testemunhos dados por visitantes ou lidos daqueles que escreviam para a Missão. Oração, momento de apelo para pessoas aceitarem Cristo, apelo à santificação ou ao batismo no Espírito Santo, e, obviamente, pregação. ${ }^{21}$

Uma tônica na igreja na comunidade de Parque Florestal é o êxtase sempre recorrente nos cultos. Para Mendonça,

O êxtase pode ser definitivamente um estado de consciência alterado, com maior ou menor intensidade, o que se caracteriza pela passagem que o indivíduo sofre de uma realidade para outra. Na maior parte das vezes o êxtase é procurado pelos indivíduos, especialmente nas práticas religiosas em que é valorizado como canal privilegiado de comunicação com o sagrado. 22

Talvez, para um pentecostal clássico, a palavra "êxtase" soe até estranho. No pensamento pentecostal, "derramar do Espírito Santo" seria mais adequado. O entendimento para essas comunidades eclesiais é que o que acontece nos cultos pentecostais é "obra do Espírito Santo". Nesse sentido, o batismo com o Espírito Santo e a

20 DURKHEIM, Émile. As formas elementares de vida religiosa. São Paulo: Paulinas, 1989. p. 72.

21 ARAÚJO, Isael de. Dicionário do Movimento Pentecostal. Rio de Janeiro: CPAD, 2007. p. 605.

22 MENDONÇA, 1997, p. 150. 
glossolalia seriam uma marca do culto pentecostal e deveria haver incentivo a tais práticas, dados os seus benefícios ao crente, individualmente, e à coletividade da congregação local. Mendonça acerta ao afirmar que esse êxtase é procurado nessas comunidades, pois de fato os pentecostais encaram o batismo com o Espírito Santo com a evidência física inicial do falar em línguas como uma preciosa "segunda bênção" a ser buscada com insistência, "até que do alto sejais revestidos de poder", (Lc24.49) como se lê e relê com frequência nessas comunidades.

\section{Testemunhos e o fator social}

"Zezé" é uma empregada doméstica que conta seu testemunho relatando que o marido era alcoólatra e estava desempregado, levando-a a sentir vontade de se separar dele, mas a falta de opção a impedia, por não ter para onde ir. Isso a impulsionou a aproximar-se da igreja, o que resultou em sua conversão. Ela foi uma das primeiras a se converter na igreja "Casa de Oração Jesus é o General".

O documentário também retrata um pouco da história de Maria Noêmia, casada, aposentada e missionária. Ela se doa à comunidade, prestando "orações fortes" em favor de curas e "abertura de porta de emprego" (expressão que é quase um idiomatismo pentecostal). Ela se sente na obrigação de repassar aquilo que ela entende como dom recebido de Deus, dádiva alcançada para ajudar as pessoas. A senhora Maria Noêmia aparece no documentário sempre acompanhada de seu marido. Ela relata que sua vida antes da conversão era marcada pelo sofrimento, tendo falta até mesmo de itens essenciais à vida, como a alimentação. Comenta ainda que tinha uma vida entregue ao vício das bebidas alcoólicas, chegando a procurar ajuda em religiões espíritas e de matriz africana para abandonar o vício, sem, contudo, obter sucesso. Foi somente quando se converteu ao evangelho que abandonou definitivamente o vício. A senhora Maria Noêmia é mencionada pelo Pastor Jamil como sendo uma missionária, que em suas andanças abre novos "trabalhos". Seu exemplo é um dentre milhares no Brasil que se doaram a esse esforço missionário no sentido de compartilhar a mensagem do evangelho.

Temos ainda citado o caso de Verenilson que, como todas as pessoas retratas no Documentário Santa Cruz, é muito simples e relata que tinha o sonho de ser alfabetizado para poder ter acesso às Escrituras Sagrada, a Bíblia. No primeiro trimestre da igreja, acontece uma mobilização por parte dos "irmãos" para a alfabetização dos seus membros, tendo como principal material didático a Bíblia Sagrada que é, ao mesmo tempo, o fator motivante dessa alfabetização.

São frequentes, nos meios pentecostais, as histórias de homens e mulheres que, jovens ou em idade avançada, e superando obstáculos e preconceitos, alfabetizaram-se e/ou adquiriram hábitos de leitura após a conversão. Assim como a alfabetização tardia pós-conversão, o letramento bíblico de iletrados e de baixo-letrados, mediante a audição dos textos canônicos por 
anos a fio, pode ser observado em comunidades espalhadas por todo o país. ${ }^{23}$

Risoneide é uma dona de casa, imigrante paraibana, retratada enfrentando um problema familiar de saúde: seu filho Daniel, de apenas três meses de idade, enfrenta uma pneumonia e permanece internado no hospital. Ela se apega ao Salmo 91, que segundo ela, é "o Salmo mais forte da Bíblia". É nesse Salmo que ela e toda comunidade se apegam para receber ajuda divina. Ele é mencionado várias vezes no documentário como sendo "o mais forte". Essa fé nesse texto bíblico encontra, ao mesmo tempo, paralelo com essa Leitura Popular da Bíblia tão presente nessas comunidades eclesiais, leitura essa que adquire um significado profundo para essas pessoas. Para Durkheim, uma religião "é um sistema solidário de crenças seguintes de práticas relativas a coisas sagradas, ou seja, separadas, proibidas; crenças e práticas que unem na mesma comunidade moral, chamada igreja, todos os que a ela aderem". ${ }^{24}$ Com efeito, é claro o esforço coletivo dos membros da igreja retratada no documentário no sentido de preservar um conjunto de valores, crenças e também em prol da alfabetização de alguns membros da igreja.

\section{O papel do Espírito Santo}

O Espírito Santo é visto como um Agente catalisador da igreja, dos membros. Como bem observa Alister E. McGrath, “o Espírito é um dom, dado por Deus, o qual une os cristãos a Deus e aos demais cristãos", 25 e essa compreensão é parte do pensamento pentecostal. É interessante ainda observar como se fala frequentemente na terceira Pessoa da Trindade no culto pentecostal, como verificado também no Documentário Santa Cruz. Ele é visto como imprescindível à salvação individual das pessoas. Donald Stamps, conhecido teólogo pentecostal, autor das notas e estudos da Bíblia de Estudo Pentecostal, ${ }^{26}$ comenta que

É essencial que os crentes reconheçam a importância do Espírito Santo no plano divino da redenção. Sem a presença do Espírito Santo neste mundo, não haveria a criação, o universo, nem a raça humana [...] Sem o Espírito Santo, não teríamos a Bíblia [...] nem o NT [...] e nenhum poder para proclamar o evangelho [...]. Sem o Espírito Santo, não haveria fé, nem novo nascimento, nem santidade e nenhum cristão neste mundo. ${ }^{27}$

A liturgia da igreja retratada no documentário é a liturgia típica das igrejas de matriz pentecostal: os cultos contam com cânticos conhecidos como "corinhos", coleta de

\footnotetext{
BENATTE, 2013, p. 92.

DURKHEIM, 1989, p. 79.

McGRATH, Alister E. Teologia sistemática, histórica e filosófica. São Paulo: Shedd Publicações, 2005. p. 368.

26 Essa obra vendeu mais de um milhão de exemplares e se tornou um grande ícone do pensamento teológico pentecostal no Brasil. Foi publicada pela Casa Publicadora das Assembleias de Deus (CPAD).

27 STAMPS. Donald. Bíblia de Estudo Pentecostal. CPAD: Rio de Janeiro, 1995. p. 1.639.
} 
ofertas e dízimos, os testemunhos e a pregação, esta última sempre marcando a parte final do culto.

\section{"Casa de Oração Jesus é o General" e a Obra Missionária}

No documentário, vemos o Pastor Jamil afirmando ter sido orientado por Deus e estar aguardando a sua direção para a implantação de um novo "templo", uma "congregação". No trimestre seguinte, o Pastor Jamil, juntamente com alguns membros de sua igreja, realizam "a obra missionária", tendo pela frente uma dura caminhada a pé até chegar a um conjunto de militares aposentados, onde eles realizam cultos nos lares, uma prática também muito comum nas igrejas pentecostais. Vemos também, já no final do documentário, alguns membros "evangelizando" dentro de coletivos, imbuídos da missão de levar a mensagem do evangelho a todas as pessoas que puderem alcançar. Esse perfil missionário da igreja liderada pelo Pastor Jamil pôde ser visto também no fato de eles acolherem e reconhecerem a senhora Maria Noêmia como uma missionária, já no início do vídeo. Esse fato é um retrato muito vívido de como as igrejas de perfil pentecostal alcançaram lugares inóspitos do país inteiro. Foi justamente esse trabalho missionário que, ainda que não tão organizado, foi em pouco tempo alcançado os estados brasileiros.

O Pentecostalismo brasileiro foi e ainda é marcado pela atuação de missionários com esse perfil, como o da senhora Maria Noêmia. Esse é um fator que não pode ser ignorado quando se analisa o crescimento vertiginoso das igrejas pentecostais no Brasil. As igrejas de linha tradicional e reformada em geral têm um crescimento muito mais tímido e lento. Os critérios adotados por essas denominações para implantação de igrejas são muito maiores do que os adotados pelas igrejas pentecostais, mormente a Assembleia de Deus que, nas palavras de Gedeon Alencar, é a "matriz pentecostal brasileira". ${ }^{28}$ Sobre esse crescimento do pentecostalismo, comenta Antonio P. Benatte:

Os pentecostais constituem hoje o segundo grupo religioso mais numeroso do país, depois dos católicos. Segundo o Censo Demográfico de 2000, o número de protestantes no Brasil alcançou 27 milhões (15\% da população), dos quais 17 milhões (10\%) são pentecostais. Do contingente pentecostal, em torno de 8 milhões $(5 \%)$ são pertencentes à Igreja Evangélica Assembleia de Deus, a maior denominação pentecostal brasileira. ${ }^{29}$

Já nos seus primórdios, a Assembleia de Deus experimentou um espantoso crescimento. O sociólogo já citado, Gedeon de Alencar, comentando sobre o contexto em que a Assembleia de Deus foi fundada, afirma que

Há muito espaço a ser conquistado. Hoje, o surgimento de uma igreja pentecostal popular não causa nenhuma alteração no cenário; ela perde-se

28 Essa expressão é título de um livro publicado pela editora Novos Diálogos, do referido autor.

29 BENATTE, 2013, p. 91. 
no meio de tantas outras. Em 1911, por ser a primeira igreja estabelecida em Belém, fez muita diferença. Tem início com vinte pessoas e, segundo Read (1976: 122), já em 1930 tem 14.000 membros, em 1950, 120.000 membros. Um crescimento de aproximadamente $69.000 \%$ em 19 anos e $108.000 \%$ em 38 anos, respectivamente. No total, mais $600.000 \%$ de crescimento nas quatro primeiras décadas, algo em torno de $15.000 \%$ ao ano. 30

A ênfase no trabalho missionário sempre foi uma tônica no Movimento Pentecostal. Vale lembrar ainda que a própria Assembleia de Deus, como representante maior do Movimento, é resultado de um empreendimento missionário e durante décadas conviveu com a supervisão e influência de missionários estrangeiros. Alencar, em Assembleias de Deus: origem, implantação e militância (1911-1946), chega a oferecer uma tabela indicativa da presença de missionários estrangeiros atuando no Brasil, abrangendo o período de 1911, ano da fundação da denominação, até 1950.31 Também no Dicionário do Movimento Pentecostal, de Isael de Araújo, encontramos um extenso artigo onde o autor traz registros históricos sobre a “Missão Americana nas Assembleias de Deus" no Brasil. ${ }^{32}$

\section{Leitura popular da Bíblia como um relevante fator social}

A compreensão da ação e da pessoa do Espírito Santo (Pneumagiologia) no Movimento Pentecostal está em estreita conexão a com a Leitura Popular que é feita da Bíblia entre os membros do movimento. Em que pese ainda o benefício social que isso traz, como reflexo, para as pessoas que integram as igrejas dentro dessa matriz. Rizoneide, uma dos membros da igreja "Casa de Oração Jesus é o General", comenta que "a Bíblia foi a escola que eu não tive", e relata que encontrou na pessoa do Pastor Jamil um tipo de acolhida que não encontrara dentro do próprio lar. Numa região de periferia, como a de Santa Cruz no Rio de Janeiro, onde o Estado não se faz presente à época do documentário, iniciativas como essas, fazem muita diferença e aliviam o sofrimento de pessoas que estão inseridas nessa realidade. O pesquisador, naturalmente, precisa ser sensível para perceber o valor dessas iniciativas que são, em essência, movidas pela convicção religiosa, mas com resultados sociais fantásticos. A Leitura Popular da Bíblia tem lugar inamovível nesse contexto, pois cria um elo entre o presente dessas pessoas com o passado bíblico. O Frei Carlos Mesters, que tão extensivamente trabalhou com o tema da Leitura Popular da Bíblia, faz um diagnóstico preciso quando comenta:

Não podemos alienar a Bíblia da vida do povo, escondendo-nos atrás de uma pretensa preocupação com a fé e com a ciência exegética. Afinal, se a Bíblia ainda tem valor e mensagem, só pode ser para nós que vivemos hoje

30 ALENCAR, Gedeon. Assembleias de Deus: origem, implantação e militância (1911-1946). São Paulo: Arte Editorial, 2010. p. 20-21.

31 ALENCAR, 2010, p. 181-183.

32 ARAÚJO, 2007, p. 465-467. 
esta nossa vida, pois não há outros para receberem, viverem e transmitirem a mensagem. ${ }^{33}$

Por mais que haja entre os pentecostais, hoje, uma notável e legítima preocupação com o fator hermenêutico na apropriação do texto bíblico, a Leitura Popular da Bíblia tem a grande vantagem de levar a Palavra viva ao povo que sofre, em diversas instâncias, e que busca se aproximar de Deus por meio de sua Palavra para encontrar nele alento e sentido para suas vidas. Nesse sentido, a Bíblia é livro que não apenas de histórias passadas, mas livro de histórias vivas porque essas mesmas histórias encontram seus paralelos nas vidas daqueles que hoje leem a Sagrada Escritura e orientam sua vida por ela. Para usar uma expressão de Mesters, a Bíblia é "livro da caminhada do povo" que "surgiu como fruto da inspiração divina e do esforço humano". 34 Desse modo, o Pentecostalismo prossegue lendo a Bíblia, como uma grande comunidade interpretativa da Palavra, levando sua mensagem e produzindo mudança social significativa na vida de tantas pessoas alcançadas por seu esforço.

\section{Conclusão}

A espiritualidade pentecostal vivida pelos membros da igreja "Casa de Oração Jesus é o nosso General" está sobre o alicerce do mover no Espírito e por uma busca por uma vida religiosa plena e satisfatória. A fé expressada nesse documentário gira em torno da experiência pessoal e é respaldada pela proximidade com o transcendente. Os cultos acontecem na espontaneidade onde não se segue roteiros, apenas um plano básico de liturgia, sendo o próprio Espírito quem conduz os cultos. Eles prezam por uma postura contra os "deleites mundanos" que, em outras palavras, são coisas profanas que desagradam a Deus. Eles têm a Bíblia como regra de fé, considerando-a como inerrante e infalível, refletindo assim uma crença básica do Pentecostalismo.

Outro ponto marcante é o batismo com Espírito Santo, que leva os membros dessa igreja a uma nova dimensão espiritual. É nesse momento, por vezes, que acontecem os "milagres", curas, profecias, prosperidade, intimidade com Deus, etc.

Mais um ponto a ser comentado é a perspectiva da santidade, e nesse sentido a igreja do Pastor Jamil vive uma unidade da fé entre os membros por uma vida futura melhor e pela maneira "'santificada" de viver. Essa comunidade pentecostal vive esse conceito, acreditando que as mudanças significativas que ocorreram em suas vidas se deram de fato pela sua aceitação da mensagem evangélica.

33 MESTERS, Carlos. Por trás das palavras: um estudo sobre a porta de entrada no mundo da Bíblia. 11.ed. Petrópolis: Vozes, 2012. p. 21.

34 MESTERS, Carlos. Flor sem defesa: uma explicação da Bíblia a partir do povo. 5.ed. Petrópolis: Vozes, 1999. p. 12-13. 
A igreja "Casa de Oração Jesus é o General" é um retrato em miniatura de todo um movimento que se espalhou não só pelo Brasil, mas pelo mundo inteiro numa proporção extraordinária, alcançando incontáveis pessoas com sua pregação. O documentário conclui de maneira interessante mostrando o que se repete em muitos lugares: os depoimentos dos membros dessa igreja sobre como praticamente uma comunidade inteira tornou-se melhor socialmente em função do contato com a mensagem do evangelho. Tornou-se comum, hoje, mesmo no próprio contexto evangélico, a crítica de que a despeito de os evangélicos serem milhões de pessoas, no Brasil, não há qualquer impacto social significativo. O Brasil continua mais corrupto e mais imoral. Mas é preciso que se levante também outras grandes questões, que parecem sempre negligenciadas nessa discussão: Como estaria o Brasil se não existissem iniciativas como essa retratada no Documentário Santa Cruz? É possível mesmo calcular isso com base em estatísticas do Instituto Brasileiro de Geografia e Estatística (IBGE) sobre a contribuição da Igreja à sociedade brasileira? Certamente essas são perguntas que evidenciam que o assunto requer mais cuidado e reflexão e um olhar interno, não apenas um olhar externo que parte de quem não vive ou não viveu a realidade da religião, da periferia e da Leitura Popular da Bíblia.

\section{Referências}

ALENCAR, Gedeon. Assembleias de Deus: origem, implantação e militância (1911-1946). São Paulo: Arte Editorial, 2010.

ARAÚJO, Isael de. Dicionário do Movimento Pentecostal. Rio de Janeiro: CPAD, 2007.

BENATTE, Antonio P. A formação de leitores da Bíblia no pentecostalismo assembleiano brasileiro. In: OLIVEIRA, David M. (Org.). Pentecostalismos e transformação social. São Paulo: Fonte Editorial, 2013.

CARVALHO, César M. Pentecostalismo e Pós-modernidade: quando a experiência sobrepõese à Teologia. Rio de Janeiro: CPAD, 2017.

Documentário Santa Cruz. Disponível em:

<www.youtube.com/watch?v=JTfWttDRPW8\&t=1776s>. Acesso em: 28 nov. 2017.

DURKHEIM, Émile. As formas elementares de vida religiosa. São Paulo: Paulinas, 1989.

GILBERTO, Antonio (Ed.). Teologia sistemática pentecostal. Rio de Janeiro: CPAD, 2008.

GRUDEM, Wayne A. Teologia Sistemática. São Paulo: Vida Nova, 1999.

McGEE, Gary B. Panorama histórico. In: HORTON, Stanley M. (Ed.). Teologia Sistemática: uma perspectiva pentecostal. 10.ed. Rio de Janeiro: CPAD, 2006.

McGRATH, Alister E. Teologia sistemática, histórica e filosófica. São Paulo: Shedd Publicações, 2005. 
McLEAN, Mark D. O Espírito Santo. In: HORTON, Stanley M. (Ed.). Teologia Sistemática: uma perspectiva pentecostal. Rio de Janeiro: CPAD, 1996.

MENDONÇA, Antonio G. Protestantes, Pentecostais e Ecumênicos: o campo religioso e seus personagens. UMESP: São Paulo, 1997.

MESTERS, Carlos. Flor sem defesa: uma explicação da Bíblia a partir do povo. 5.ed. Petrópolis: Vozes, 1999.

. Por trás das palavras: um estudo sobre a porta de entrada no mundo da Bíblia.

11.ed. Petrópolis: Vozes, 2012.

RICHARDS, Lawrence O. Comentário histórico-cultural do Novo Testamento. 3.ed. Rio de Janeiro: CPAD, 2008.

SALES, João M. Disponível em: <educacao.uol.com.br/biografias/joao-moreirasalles.jhtm>. Acesso em: 28 nov. 2017.

SANCHES, Regina F. Contribuições de uma Teologia Bíblica Integral do Espírito Santo para a Pneumatologia Pentecostal. In: OLIVEIRA, David M. (Org.). Pentecostalismos e transformação social. São Paulo: Fonte Editorial, 2013.

SCHÜLER, Arnaldo. Dicionário enciclopédico de teologia. Canoas: ULBRA, 2002.

STAMPS. Donald. Bíblia de Estudo Pentecostal. CPAD: Rio de Janeiro, 1995. 